\title{
Kinetics of Transformation of Calcite to Fluorapatite Under Flow Conditions
}

\author{
ABHAS SINGH, ARAVINTH SIVA SUBRAMANIAM \\ EKAMPARAM AND SURYA SUJATHAN
}

Indian Institute of Technology Kanpur

Presenting Author: abhas@iitk.ac.in

Fluoride (F) contamination in groundwater affects millions of people across the world. Recent investigations on phosphateinduced $\mathrm{F}$ immobilization on calcite resulted in the formation of the highly stable mineral fluorapatite $\left(\mathrm{Ca}_{5}\left(\mathrm{PO}_{4}\right)_{3} \mathrm{~F} ; \mathrm{FA}\right)$ at room temperature. The objective of this study was to quantify the kinetics of calcite transformation to fluorapatite in the presence of fluoride $(\mathrm{F})$ and phosphate $\left(\mathrm{PO}_{4}\right)$ in ultrapure water. Flowthrough reactor experiments were conducted under varying flow rates $\left(0.01-0.04 \mathrm{~mL} \cdot \mathrm{min}^{-1}\right)$ and inlet fluoride concentrations $(0.1$ $\left.0.4 \mathrm{mM} ; 2-8 \mathrm{mg} \cdot \mathrm{L}^{-1}\right)$, with with a constant and critical level of inlet $\mathrm{PO}_{4}$ concentration $(1 \mathrm{mM})$. Control studies with calcite, in the presence of only fluoride or only phosphate, were also performed for all flow rates. Effluent samples were collected at predefined time intervals using a fraction collector, and measured for $\mathrm{pH}$ and total dissolved $\mathrm{F}, \mathrm{Ca}$, and $\mathrm{PO}_{4}$ concentrations. Elution data were modeled by applying mass balance on continuously stirred tank reactors to determine surface normalized $\mathrm{F}$ uptake rate constants on calcite, as it transforms to FA. Processes such as dissolution of calcite, adsorption of $\mathrm{F}$ and $\mathrm{PO}_{4}$ onto calcite, and precipitation of FA and hydroxyapatite were considered in the model. The rates of precipitation of hydroxyapatite and fluorapatite were modeled as $\sim 10^{-15}$ and $\sim 10^{-26} \mu \mathrm{mol} \cdot \mathrm{m}^{-2} \cdot \mathrm{min}^{-1}$, respectively (Fig. 1). Estimation of FA reaction kinetics can potentially be helpful in quantifying time-scales of $\mathrm{F}$ transport and treatment of F-contaminated waters with mild phosphate and calcite amendments, which is likely to promote stable immobilized forms of F.

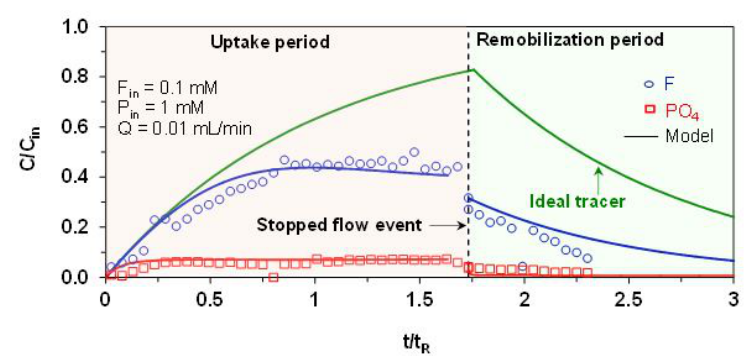

Figure 1. Variation of fluoride and phosphate with time in the presence of calcite. During the uptake period, a solution containing fluoride and phosphate was passed through the reactor At the end of this period, the reactor was subjected to a $24 \mathrm{~h}$ stopped flow event (dashed line) Subsequently, during the remobilization period ultrapure water was passed through the reactor. The hydraulic residence time (tR) was $96 \mathrm{~h}$. 